\title{
Mechanism Identification and Kinetics Analysis of Thermal Degradation for Carbon Fiber/Epoxy Resin
}

\author{
Han Li, Nasidan Wang, Xuefei Han, Haoran Yuan and Jiang Xie *
}

check for updates

Citation: Li, H.; Wang, N.; Han, X.; Yuan, H.; Xie, J. Mechanism Identification and Kinetics Analysis of Thermal Degradation for Carbon Fiber/Epoxy Resin. Polymers 2021, 13, 569. https://doi.org/10.3390/ polym13040569

Academic Editor: Bon-Cheol Ku

Received: 10 January 2021

Accepted: 9 February 2021

Published: 14 February 2021

Publisher's Note: MDPI stays neutral with regard to jurisdictional claims in published maps and institutional affiliations.

Copyright: (c) 2021 by the authors. Licensee MDPI, Basel, Switzerland. This article is an open access article distributed under the terms and conditions of the Creative Commons Attribution (CC BY) license (https:/ / creativecommons.org/licenses/by/ $4.0 /)$.
College of Airworthiness, Civil Aviation University of China, Tianjin 300300, China; cauc_lihan@126.com (H.L.); nsdwang@163.com (N.W.); hanxuefei185@163.com (X.H.); yhr18041363619@163.com (H.Y.)

* Correspondence: h-li@cauc.edu.cn or xiejiang5@126.com

\begin{abstract}
For carbon fiber epoxy resin used in aerostructure, thermal degradation mechanism and kinetics play an important role in the evaluation of thermal response and combustion characteristics. However, the thermal decomposition process and mechanism are difficult to unify strictly due to the complexity of the components from different suppliers. In the present study, a product of carbon fiber epoxy resin made by AVIC (Aviation Industry Corporation of China) composite corporation is examined to identify its thermal degradation mechanism and pyrolysis products by measurements, including simultaneous thermal analysis, Fourier transform infrared spectroscopy and mass spectrometry, establish the kinetic model by Kissinger/Friedman/Ozawa/Coats-Redfern methods. The results show thermal degradation occurs in three steps under the inert atmosphere, but in four steps under air atmosphere, respectively. The first two steps in both environments are almost the same, including drying, carbon dioxide escape and decomposition of the epoxy resin. In the third step of inert atmosphere, phenol is formed, methane decreases, carbon monoxide basically disappears and carbon dioxide production increases. However, in air, thermal oxidation of the carbonaceous residues and intermolecular carbonization are observed. Furthermore, thermal degradation reaction mechanism submits to the $\mathrm{F}_{4}$ model. These results provide fundamental and comprehensive support for the application of carbon fiber epoxy resin in aircraft industry.
\end{abstract}

Keywords: thermal degradation; kinetics; gas analysis; carbon fiber/epoxy resin

\section{Introduction}

Attributed to high resistance to corrosion, high specific strength and stiffness of FRP (Fiber Reinforced Polymer) material, its utilization in infrastructures and manufacturing is more and more popular. For example, concrete slabs with GFRP(Glass Fiber Reinforced Polymer) bars and hallow composite reinforcing system [1] and a novel prefabricated FRP composite jacket with an easy-fit and self-locking mechanical joining system [2] have been developed. In addition, carbon fiber epoxy resin has been widely used in the design and manufacture of aircraft load-bearing and functional structures. However, thermal behavior of FRP is completely different from that of aluminum, because it can soften, decompose and burn to release fumes, especially in fire, leading to threaten the safety of occupants. As a result, both the Federal Aviation Administration (FAA) and the European Aviation Safety Agency (EASA) require us to consider fire protection, flame retardancy, combustion product toxicity, and other thermal issues of composite aircraft structures in airworthiness certification [3]. For this reason, the generic material combustion computational model, ThermaKin [4-7] and a toxicity assessment model [8-10] have been developed by FAA. In addition, Tranchard [11] developed a material thermal response model based on SEMCEF for fire environments and validated it with the T700/M21 composite material used in Airbus 350. Li [12,13] also developed a thermal response model for composites in the fire environment based on ABAQUS.

Thermal response and combustion characteristics of carbon fiber epoxy resin in the fire environment mainly depends on the thermal decomposition of resin matrix. For this 
reason, Quintiere [14] has conducted reaction kinetic parameter tests, thermophysical property tests and flame retardant performance tests on fiber epoxy resins conforming to the Boeing Material Specification. Tranchard $[15,16]$ also carried out similar tests on T700/M21 to obtain the reaction kinetic parameters of the material and to establish the reaction kinetic model, and to explore decomposition mechanism and the combustion products. Reaction kinetic parameters, including activation energy, reaction order and the pre-exponential factor, are typically obtained by the thermal analysis. The combination of thermal analysis and infrared or mass spectrometry analysis can more accurately analyze the reaction process and mechanism. Considerable progress has been made in modeling of kinetic [17-23], including multi- or single-step kinetic models that can be utilized in thermal-mechanical model [24], lightning strikes [25], fire behavior [11], curing process design, fiber recycling [26,27], etc.

Moreover, the complexity and even uncertainty of components of composites lead to a large amount of kinetics and mechanism research. Ahamad and Alshehri [28] studied the thermal degradation behavior of UF/epoxy resin blends (UFE) using a thermogravimetric analysis (TGA), Fourier transform infrared (FTIR) spectra and mass spectrometry (MS) to identify decomposition products such as $\mathrm{CO}_{2}, \mathrm{CO}, \mathrm{H}_{2} \mathrm{O}, \mathrm{HCN}, \mathrm{HNCO}$ and $\mathrm{NH}_{3}$, and established a reaction kinetic model using the Coats-Redfern method to clarify the main decomposition mechanisms. $\mathrm{Li}$ and $\mathrm{Wu}[29]$ studied the pyrolysis performance and flame-retardant mechanism of flame retardant EP with respect to the synthetic amino resin intumescent flame retardant (AIFR), showing that AIFR advances the pyrolysis of $\mathrm{EP}$, reduces the activation energy of pyrolysis, increases the residual carbon and decreases the intensity of the absorption peak in the infrared spectrum. Liu et al. [30] investigated the curing reaction of bisphenol A formaldehyde phenolic epoxy resin (bisANER) with diaminodiphenyl ether (DDE) and the thermal degradation properties of its cured products, and calculated the activation energy of bis-ANER/DDE non-isothermal curing reaction by the Kissinger method and Ozawa-Flynn-Wall method, also determined the thermal degradation mechanism under different atmospheres. Huang et al. [31] used thermogravimetric mass spectrometry to investigate the pyrolysis reaction behavior of the amino-phenolic resin. The kinetic parameters of the pyrolysis reaction of amino-phenolic resin were obtained by the kinetic analysis of the experimental data using the Coats-Redfern integration method, and the decomposition mechanism and pyrolysis products were clarified. Thomas et al. [32] used the standard Flynn-Wall-Ozawa (FWO) method to deduce the Arrhenius parameters from thermograms of biosourced substrates, hence, the energy of activation $\left(\mathrm{E}_{\mathrm{a}}\right)$ was obtained. Balart et al. [33] studied systematic kinetics of the thermal degradation of recycled ABS in inert atmosphere with using Flynn-Wall-Ozawa (FWO), the Kissinger-Akahira-Sunose (KAS) and the Starink methods, and suggested the degradation process of ABS takes place in a single-step process. Franco-Urquiza et al. [34] performed the thermogravimetric analysis at 5,10 and $20^{\circ} \mathrm{C} / \mathrm{min}$ allowed determining the degradation kinetic parameters based on the Friedman and Kissinger models for neat polyester and nanocomposites, which showed that heating rates promoted an increase in the temperature degradation. Krawiec et al. [35] used a testing methodology to determine the toxicometric indicators on belts made of classically used fabric-rubber composite material, and evaluated the degradation kinetics of the polymeric belts by (TGA). Zhang et al. [36] investigated the effect of basalt fiber content in HDPE matrix composites on the thermal decomposition process using dynamic thermogravimetric analysis and utilized improved Coats-Redfern (C-R), Flynn-Wall-Ozawa (F-W-O), Friedman and Kissinger methods to ascertain the specific apparent activation energy $\left(\mathrm{E}_{\mathrm{a}}\right)$ of each component and composite material.

Therefore, for whether a new material or material modification, it is necessary to carry out thermal analysis, identify the thermal behavior or mechanism of degradation and establish the kinetic model. For carbon fiber epoxy resin used in aerostructure, it usually consists of a fiber, epoxy monomer, curing agent, catalyst and flame retardant, with complex composition and content. Therefore, the thermal decomposition process and mechanism of products from different suppliers are difficult to unify strictly. In this paper, 
for a new product of carbon fiber reinforced epoxy resin composite, BA3202, developed by AVIC (Aviation Industry Corporation of China) composite corporation for aerostructures, simultaneous thermal analysis (STA), FTIR spectra and mass spectrometry (MS) were conducted to obtain the reaction kinetic parameters, and a degradation kinetic model was established based on the Kissinger/Friedman/Ozawa/Coats-Redfern methods. Moreover, the thermal decomposition products of the material were identified to clarify the reaction mechanism. Compared to the published study in literature, a more comprehensive and thorough insight into thermal behavior of CFRP used in aerostructures is presented, and detailed data can support thermal response modeling, combustion modeling and toxicity assessment of material in fire.

\section{Materials and Methods}

Samples of carbon fiber reinforced epoxy resin matrix composite material used for aerostructures were provided by AVIC composite corporation (Beijing, China), in which matrix is mainly DGEBA. The preparation process was prepreg cutting-lay-up-autoclave molding-machining. The size of sample was $4 \mathrm{~mm} \times 4 \mathrm{~mm} \times 1.2 \mathrm{~mm}$ with the lamina thickness of prepreg of $0.15 \mathrm{~mm}$, shown as Figure 1 . Stacking sequence is [0/45/90/135]s with the fiber volume of $54 \%$ and the density of $1.55 \mathrm{~g} / \mathrm{cm}^{3}$.
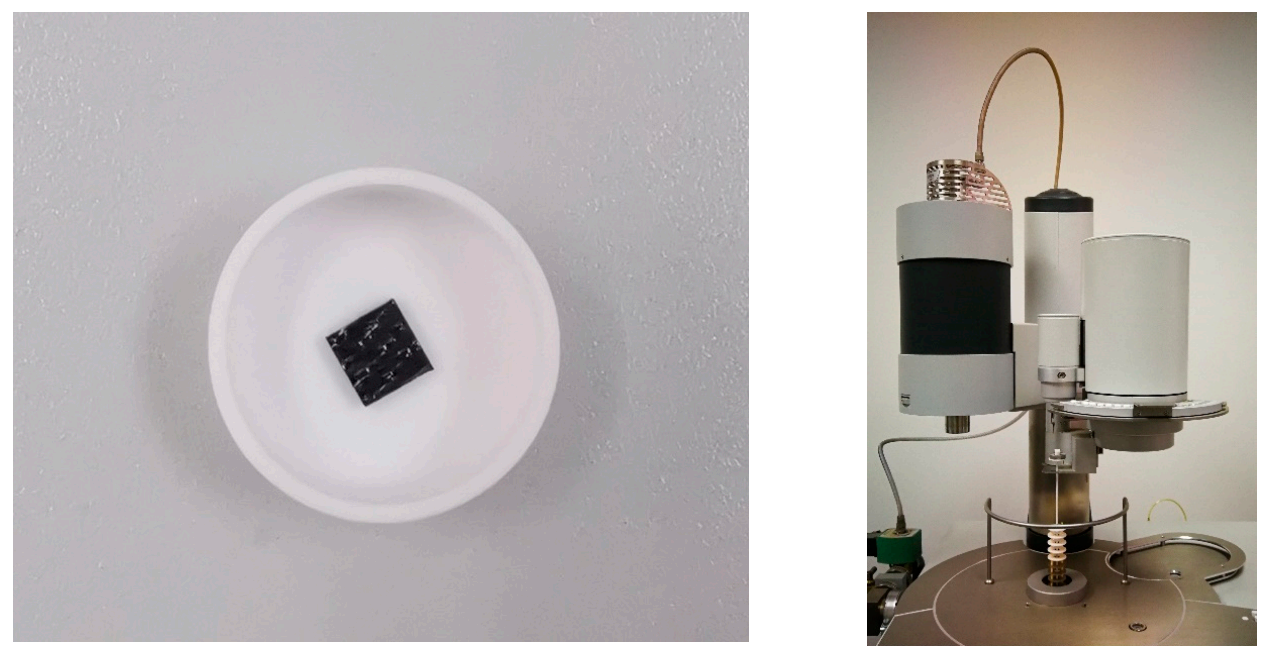

Figure 1. Specimen in the crucible and placement in the equipment.

Thermal analysis experiments were performed using the simultaneous thermal analyzer (NETZSCH STA 449 F3, NETZSCH, Selb, Germany), FTIR spectrometer (BRUKER VERTEX 80, BRUKER, Billerica, MA, USA) and mass spectrometry (NETZSCH QMS403C, NETZSCH, Selb, Germany) to investigate the mass changes (TG, Thermogravimetric), derivative of mass changes (DTG, Derivative Thermogravimetric) and gas composition (FTIR/MS), referring to the test standards [37-40]. The sample used in the simultaneous thermal analyzer was heated from room temperature to $1100^{\circ} \mathrm{C}$ at the heating rates of 5 , 10,20 and $40^{\circ} \mathrm{C} / \mathrm{min}$, under the atmosphere of air and inert gas, respectively, with the purge flow rate set to $20 \mathrm{~mL} / \mathrm{min}$. The primary aim of the TG analyses was to know the thermal degradation characteristics of materials, and to obtain adequate data to perform kinetic analysis in order to obtain the Arrhenius parameters. IR spectra were recorded in the spectral range of 4500-650 $\mathrm{cm}^{-1}$ with a resolution of $4 \mathrm{~cm}^{-1}$ and an average number of scans of 16 . The intensities of 17 ions $(m / z=14,16,17,18,26,28,30,42,44,46,56,60,64$ and 94$)$ were determined according to the previous work [16,41]. 


\section{Results and Discussion}

\subsection{Thermal Degradation}

Figure 2 shows the TG and DTG curves of carbon fiber reinforced epoxy resin matrix composite heated from room temperature to $1100{ }^{\circ} \mathrm{C}$ at $20^{\circ} \mathrm{C} / \mathrm{min}$ under air and inert atmosphere, respectively. Under inert atmosphere, the TG curve shows three mass loss stages, corresponding to three DTG curve peaks. The first stage of weight loss ranged from room temperature to $286{ }^{\circ} \mathrm{C}$ with the mass loss of $0.69 \%$, and the maximum weight loss rate was $0.17 \% / \mathrm{min}$ with the peak temperature of $244{ }^{\circ} \mathrm{C}$. At this stage, physical escape of lowmolecular-weight gases occurs, with the drying effect caused by the temperature rise from room temperature, where water was evaporated rapidly, justified by mass spectrometry in Section 3.3.2. The same drying process is also observed in thermos-gravimetric analysis of epoxy resins by Ahamad [28] and Shao [42].

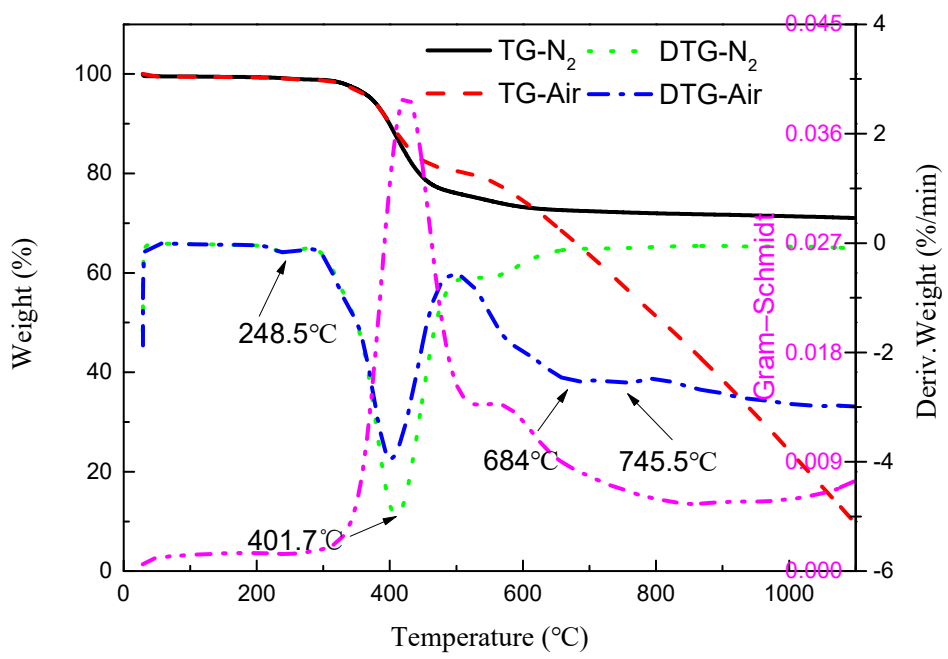

Figure 2. TG and DTG curves for the carbon/epoxy composite material carried out under inert and air atmosphere at $20^{\circ} \mathrm{C} / \mathrm{min}$.

The second stage ranged from 286 to $515{ }^{\circ} \mathrm{C}$ with the mass loss of $23.29 \%$, where the maximum weight loss rate was $4.99 \% / \mathrm{min}$ at the peak temperature of $410{ }^{\circ} \mathrm{C}$. This range is close to the pyrolysis interval of epoxy resin, where the ether bond is broken to generate BPA (Bisphenol-A), and the phenol comes from the further decomposition of BPA and/or the breakage of the $\mathrm{C}-\mathrm{C}$ bond connecting the benzene ring after the breakage of unilateral ether bond on the epoxy resin [43], which is an obvious degradation behavior of the resin matrix. The weight loss of $4.54 \%$ in the third stage occurred in a wide temperature range from 515 to $1100{ }^{\circ} \mathrm{C}$, which was relatively gentle, and the maximum loss rate was $0.64 \% / \mathrm{min}$ corresponding to the peak temperature of $537.4{ }^{\circ} \mathrm{C}$. According to the literature [44], the pyrolysis temperature of BPA epoxy resin is higher than $660^{\circ} \mathrm{C}$, so this stage was considered as further pyrolysis of the polymer [28].

Under the air atmosphere, the specimen was almost completely degraded with the mass loss of $90.64 \%$ reached at $1100{ }^{\circ} \mathrm{C}$. The existence of four peaks in the DTG curve indicated that the weight loss process was divided into four stages, and the peak temperature was shown in Figure 1. The characteristics of the first weight loss stage in air atmosphere was almost consistent with that in inert gas, which was a typical drying stage. The peak temperature in the second stage was only slightly lower, but the pyrolysis interval was also similar to that under the inert atmosphere, indicating that the degradation of the resin matrix also occurred at this stage. Therefore, it showed that the reaction atmosphere has less influence on the degradation reaction of the resin matrix. However, the percentage of weight loss and weight loss rate in the inert atmosphere were greater.

The temperature range of the third stage was from 497 to $710{ }^{\circ} \mathrm{C}$ with the mass loss of $18.38 \%$, the maximum weight loss rate of $2.53 \% / \mathrm{min}$ and the peak temperature of $684{ }^{\circ} \mathrm{C}$. 
Thermal oxidation of intermediate transient carbonaceous residues [16], which is a process of intermolecular cross-linking, carbonization, and further removal of small molecules, occurred at this stage [29]. The weight loss in the fourth stage ranged from 710 to $1100{ }^{\circ} \mathrm{C}$ with the mass loss of $52.65 \%$; the maximum weight loss rate was $2.55 \% / \mathrm{min}$, and the peak temperature was $745.5^{\circ} \mathrm{C}$. This was due to the reaction of the carbon fiber reinforced material with oxygen and the nearly complete oxidative decomposition of the carbon fiber caused by prolonged heating, which was supported by literature [45].

\subsection{Kinetic Model}

Figure 3 shows the TG and DTG curves at different heating rates under inert and air atmosphere. Two inflection points appeared in the TG curves for different heating rates under inert atmosphere, which corresponded to the two peaks of the DTG curve. As the temperature rise rate increases, the weight loss curve shifts to the higher temperature region [46]. However, in air atmosphere, the effect of the temperature rise rate on weightloss behavior appears more complex due to the oxidative decomposition of carbon fiber. The lower the temperature rise rate is, the longer the time is to reach the same temperature, and so the more sufficient the reaction is. As a result, the two lower heating rates ( 5 and $10^{\circ} \mathrm{C} / \mathrm{min}$ ) make the temperature at which the weight loss rate reached the peak value lower, so that two more peaks could be seen below $1000^{\circ} \mathrm{C}$. However, under the heating rates of 20 and $40^{\circ} \mathrm{C} / \mathrm{min}$, the degradation was not completed within $1100{ }^{\circ} \mathrm{C}$, and no corresponding peaks were observed.

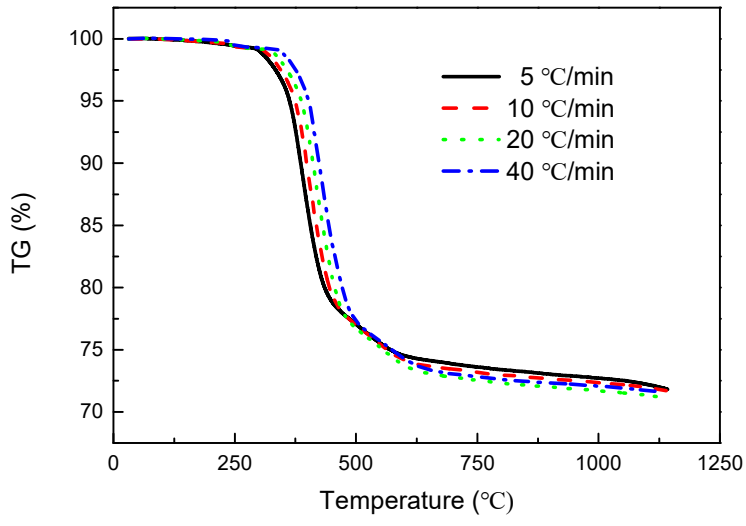

(a)

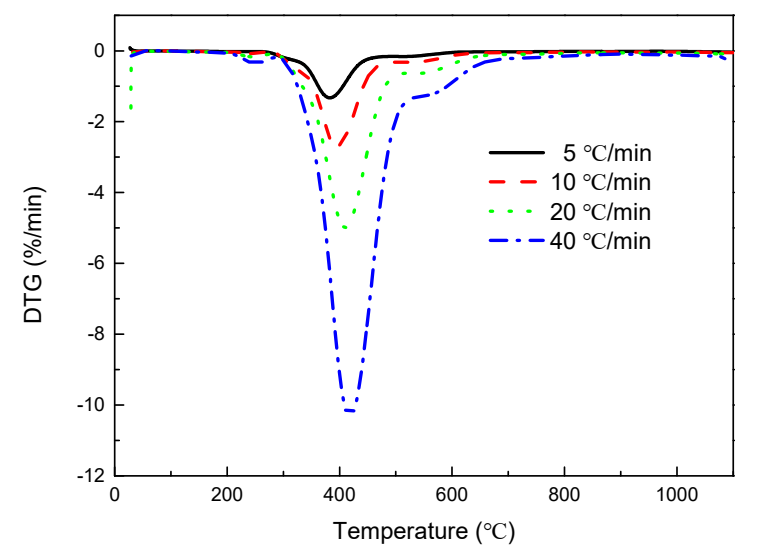

(c)

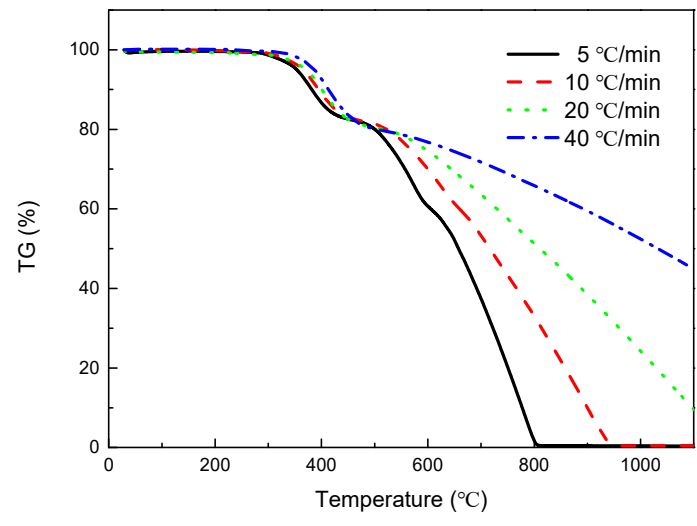

(b)

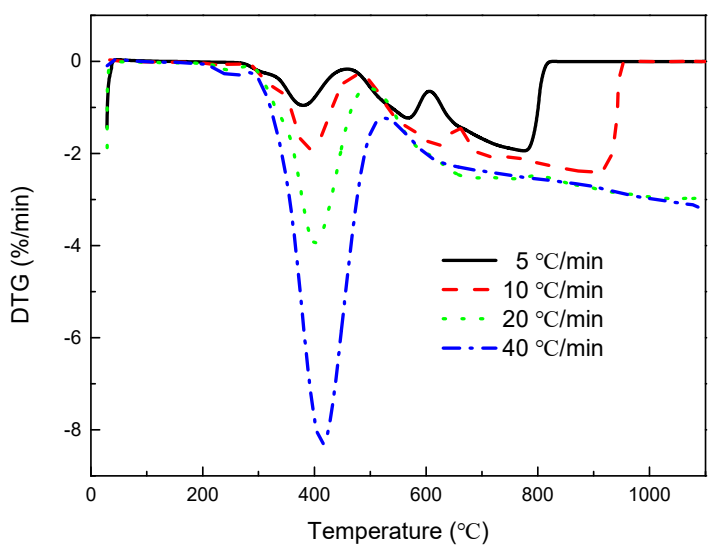

(d)

Figure 3. (a) TG curves and (c) DTG curves under inert atmosphere; (b) TG curves and (d) DTG curves under air atmosphere for T300/Epoxy composites at 5, 10, 20 and $40{ }^{\circ} \mathrm{C} / \mathrm{min}$. 
The different methods for solving the kinetic constants of reactions are based on the same basic theoretical formula derived from the Arrhenius formula, as shown in the following equation:

$$
\frac{d \alpha}{d t}=A \exp \left(\frac{-E_{A}}{R T}\right) f(\alpha),
$$

where $\alpha=\left(M_{i}-M\right) /\left(M_{i}-M_{\mathcal{e}}\right)$ is the conversion degree, $M_{i}, M, M_{\mathcal{e}}$ are the initial mass, the mass of the specimen at the current moment, and the final mass at the end of the reaction, respectively. $f(\alpha)$ is a function of the kinetic mechanism, which is a function of the conversion degree, depending on the specific degradation mechanism. $\mathrm{R}$ is the ideal gas constant, with a value of $8.314 \mathrm{~J} /(\mathrm{mol} \mathrm{K})$.

In this paper, the kinetic parameters of the reaction were solved by the Kissinger [47] differential method, the Friedman [20] differential method and the Ozawa [22] integral method, respectively. These three methods did not require the degradation reaction mechanism of the material to obtain the activation energy. As to calculate the reaction order, it can be assumed that the mechanism function can be expressed as follows: $f(\alpha)=(1-\alpha)^{n}$. The Kissinger method [47] assumes the maximum reaction rate at the peak temperature. The Friedman method [20] assumes that the reaction kinetic constant $A, E_{A}$ and $\mathrm{n}$ are independent of the heating rate. While the Ozawa method [22] assumes that the conversion degree at the peak temperature at different heating rates is a constant (iso-conversion method). Additionally, the Coats-Redfern method was used to determine the reaction mechanism function. The data obtained under inert atmosphere are shown in the following Table 1.

Table 1. Kinetic parameters by Kissinger, Friedman and Ozawa methods.

\begin{tabular}{cccc}
\hline Method & $\alpha$ & $E_{A} /(\mathbf{k J} / \mathbf{m o l})$ & $A / \mathbf{m i n}^{-1}$ \\
\hline \multirow{2}{*}{ Kissinger } & & 264.671 & $3.088 \times 10^{24}$ \\
& & 216.508 & $3.14 \times 10^{13}$ \\
\hline \multirow{3}{*}{ Friedman } & 0.2 & 211.957 & \\
& 0.3 & 215.000 & \\
& 0.4 & 217.153 & $1.343 \times 10^{14}$ \\
& 0.5 & 222.009 & \\
& 0.6 & 221.851 & $1.775 \times 10^{14}$ \\
Ozawa & 0.7 & 285.503 & $9.12 \times 10^{14}$ \\
& 0.2 & 181.670 & $5.1 \times 10^{14}$ \\
& 0.3 & 194.279 & $2.89 \times 10^{14}$ \\
& 0.4 & 198.611 & $1.56 \times 10^{14}$ \\
& 0.5 & 202.817 & $7.54 \times 10^{13}$ \\
\hline
\end{tabular}

\subsubsection{Kissinger Method}

Differentiation on both sides of (1) yields the following equation:

$$
\frac{E_{A} \beta}{R T_{m}^{2}}=A n\left(1-\alpha_{m}\right)^{n-1} \exp \left(\frac{-E_{A}}{R T_{m}}\right),
$$

where $T_{m}$ is the peak temperature from the DTG curve, $\alpha_{m}$, is the peak conversion corresponding to $T_{m}$, which is obtained from the TG curve, and $\beta=\frac{d T}{d t}$ is the constant heating rate during the experiment. Kissinger considers $n\left(1-\alpha_{m}\right)^{n-1}$ is independent of $\beta$ and its value is approximately equal to 1 .

The activation energy can be obtained from the above equation by logarithm and derivation:

$$
\frac{d\left(\ln \left(\beta / T_{m}^{2}\right)\right)}{d\left(1 / T_{m}\right)}=-\frac{E_{A}}{R}
$$


The thermal weight loss process of carbon fiber reinforced epoxy resin composites under inert atmosphere has two main stages. As shown in Figure 4, the intercept and slope data are obtained.

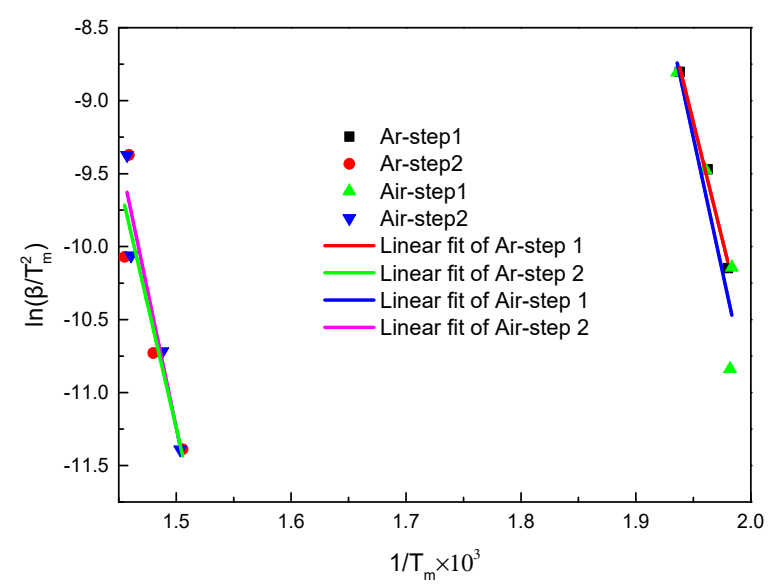

Figure 4. Plots of $\ln \left(\beta / T_{m}^{2}\right)-1 / T_{m}$ by Kissinger method under inert and air atmosphere.

The relationship between the pre-exponential factor $A$, and the slope and intercept of the curve is as follows:

$$
\ln (A /(-k))=a,
$$

When calculating the reaction order $n$, consider the mechanism function to be expressed as $f(\alpha)=(1-\alpha)^{n}$ and $n$ is calculated by the following equation:

$$
-n\left(1-\alpha_{m}\right)^{n-1}=1+(n-1) \frac{2 R T_{m}}{E_{A}},
$$

The results are shown in the Table 2 below:

Table 2. Kinetic parameters by Kissinger method.

\begin{tabular}{cccccc}
\hline \multicolumn{2}{c}{ Reactions } & \multicolumn{2}{c}{ Step 1 } & \multicolumn{2}{c}{ Step 2 } \\
\hline \multicolumn{2}{c}{ Atmosphere } & Ar & Air & Ar & Air \\
\hline $\begin{array}{c}\text { Activation } \\
\text { energy }\end{array}$ & $E_{A} /\left(\mathrm{kJ}^{\prime} \mathrm{mol}^{-1}\right)$ & 264.671 & 301.884 & 216.508 & 313.307 \\
$\begin{array}{c}\text { Pre-exponential } \\
\text { factor }\end{array}$ & $A / \mathrm{min}^{-1}$ & $3.088 \times 10^{24}$ & $1.96 \times 10^{28}$ & $3.14 \times 10^{13}$ & $1.75 \times 10^{21}$ \\
$\quad \begin{array}{l}\text { Order } \\
\text { n }\end{array}$ & $\mathrm{n}$ & 0.94 & 0.93 & 0.96 & 0.945 \\
\hline
\end{tabular}

\subsubsection{Friedman Method}

Taking the logarithm of (1) gives the following equation

$$
\ln \left(\beta \frac{d \alpha}{d T}\right)=\ln (A)+n \ln (1-\alpha)-\left(\frac{E_{A}}{R T}\right),
$$

where $\ln \left(\beta \frac{d \alpha}{d T}\right)=\ln \left(\frac{d \alpha}{d t}\right)$.

The relationship between $\ln \left(\frac{d \alpha}{d t}\right)$ and $1 / T$ at different conversion degrees was calculated as shown in Figure 5. 


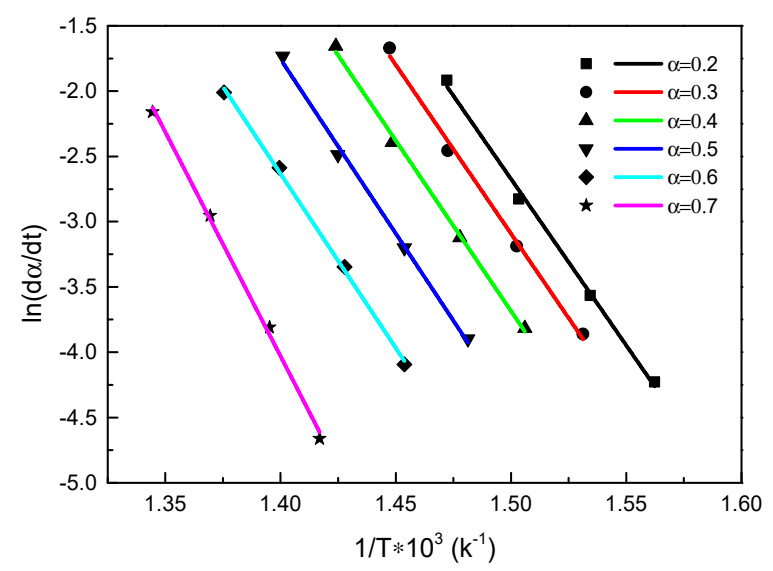

Figure 5. Plots of $\ln \left(\frac{d \alpha}{d t}\right)-1 / \mathrm{T}$ by the Friedman method under inert atmosphere.

Figure 6 shows a line chart of the activation energy with conversion degree, which illustrates that the activation energy is not a constant, but changes as the thermal decomposition reaction proceeds and the conversion degree increases, showing an overall upward trend. Therefore, the thermal decomposition reaction of carbon fiber reinforced epoxy composite under inert gas is a multi-step. Furthermore, the predominant factor was found to be $1.34287 \times 10^{14}$.

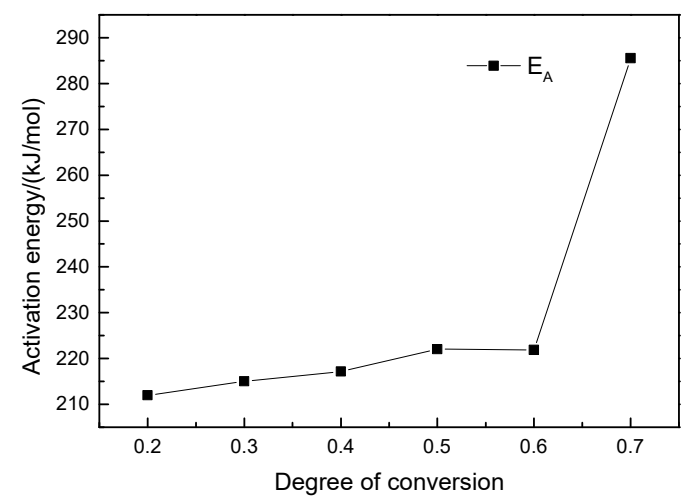

Figure 6. Activation energy as a function of fractional mass loss by the Friedman method under inert atmosphere.

\subsubsection{Ozawa Method}

The activation energy $E_{A}$ was calculated by the following formula:

$$
E_{A}=-\frac{R}{0.4567} \frac{d(\log \beta)}{d(1 / T)},
$$

The relationship between $\log \beta$ and $1 / T$ was calculated for different conversion degrees as shown in the following Figure 7: 


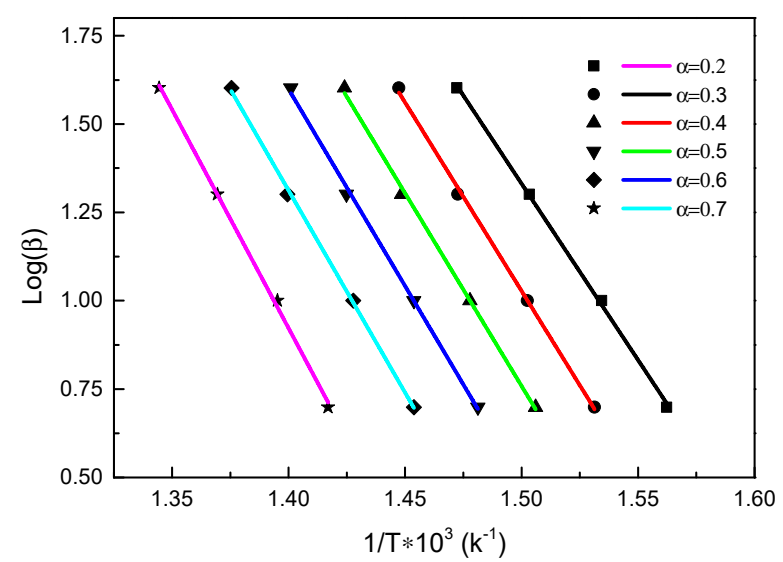

Figure 7. Plots of $\log \beta-1 / T$ by the Ozawa method under inert atmosphere.

The pre-exponential factor was calculated by the following formula [48,49]:

$$
\log A=\log \beta+\log E_{A}+0.434 E_{A} / R T-\log R-2 \log T,
$$

At the same conversion degree, yielding the values of the corresponding pre-exponential factor for different heating rates, as shown in Figure 8. And the mean values were finally obtained. The activation energies obtained by Ozawa's method were similar to those obtained by Friedman's method, which verified the accuracy of the results.

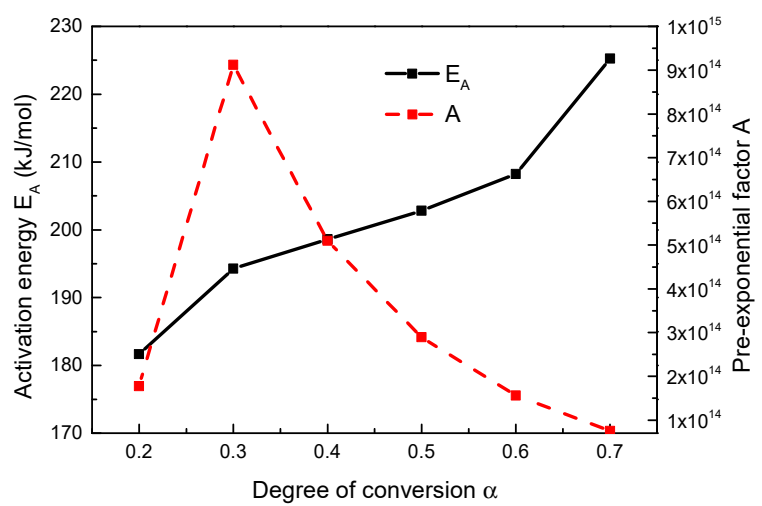

Figure 8. Activation energy and pre-exponential factor as function of fractional mass loss by Ozawa method under inert atmosphere.

\subsubsection{Coats-Redfern Method}

Coats and Redfern assumed the function of the kinetic mechanism is $f(\alpha)=(1-\alpha)^{n}$, and derived the following expression:

$$
\ln \left(\frac{\alpha}{T^{2}}\right)=\ln \left(\frac{A R}{\beta E_{A}}\right)\left[1-\left(\frac{2 R T}{E_{A}}\right)\right]-\left(\frac{E_{A}}{R T}\right),
$$

where $\alpha$ in the logarithmic term of the left equation is the result of integrating $1 / f(\alpha)$ to $\alpha$ and then ignoring higher-order terms under the condition of low conversion rate after polynomial expansion. In order to study the kinetic model of thermal decomposition, assuming that the mechanism function is unknown, the alternative term to $\alpha$ in the logarithmic term is the integral form $F(\alpha)$ of $1 / f(\alpha)$, and considering that $\frac{2 R T}{E_{A}}$ approaches zero, the formula is as follows:

$$
\ln \left(\frac{F(\alpha)}{T^{2}}\right)=\ln \left(\frac{A R}{\beta E_{A}}\right)-\left(\frac{E_{A}}{R T}\right),
$$

Different mechanism models were established by this method, as shown in Table 3. 
Table 3. Thirteen kinds of commonly used pyrolysis kinetics models.

\begin{tabular}{ccc}
\hline Mechanism & $\boldsymbol{F ( \alpha )}$ & Reaction Mechanism \\
\hline $\mathrm{F}_{1}$ & $-\ln (1-\alpha)$ & One-dimensional random nuclear reaction \\
\hline $\mathrm{F}_{2}$ & $\frac{1}{1-\alpha}$ & Two-dimensional random nucleation reaction \\
\hline $\mathrm{F}_{3}$ & {$\left[(1-\alpha)^{2}\right.$} & Three-dimensional random nuclear reaction \\
\hline $\mathrm{F}_{\mathrm{n}}$ & {$[-\ln (1-\alpha)]^{1 / 2}$} & $n$th order \\
\hline $\mathrm{A}_{2}$ & {$[-\ln (1-\alpha)]^{1 / 3}$} & Avrami random nucleation $n=2$ \\
\hline $\mathrm{A}_{3}$ & {$[-\ln (1-\alpha)]^{1 / 4}$} & Avrami random nucleation $n=3$ \\
\hline $\mathrm{A}_{4}$ & $1-(1-\alpha)^{1 / 2}$ & Avrami random nucleation $n=4$ \\
\hline $\mathrm{R}_{2}$ & $1-(1-\alpha)^{1 / 3}$ & Phase boundary reaction, cylindrical symmetry \\
\hline $\mathrm{R}_{3}$ & $\alpha^{2}$ & Phase boundary reaction, spherical symmetry \\
\hline $\mathrm{D}_{1}$ & $(1-\alpha) \ln (1-\alpha)+\alpha$ & \begin{tabular}{c} 
One-dimensional diffusion \\
\hline $\mathrm{D}_{2}$
\end{tabular} \\
\hline $\mathrm{D}_{3}$ & {$\left[1-(1-\alpha)^{1 / 3}\right]^{2}$} & $\begin{array}{c}\text { Two-dimensional diffusion, cylindrical } \\
\text { symmetry, (Valensi equation) }\end{array}$ \\
\hline $\mathrm{D}_{4}$ & $(1-2 \alpha / 3)-(1-\alpha)^{2 / 3}$ & $\begin{array}{c}\text { Three-dimensional diffusion, spherical } \\
\text { symmetry Jander equation }\end{array}$ \\
\hline
\end{tabular}

The $\ln \left(\frac{F(\alpha)}{T^{2}}\right)-1 / T$ curves for the conversion rates from 0.2 to 0.7 at different heating rates were made to obtain the activation energy values. Pearson's correlation coefficients were calculated to measure the correlation between the variables, as shown in Table 4 . Comparing the activation energy values in Table 4 with those calculated by the three kinetic methods in Table 1. The average $\mathrm{E}_{\mathrm{A}}$ of $\mathrm{F}_{4}$ is the closest to the previous calculation, which was $211.691 \mathrm{~kJ} / \mathrm{mol}$. It is concluded that the pyrolysis reaction of carbon fiber reinforced epoxy resin composite in the inert atmosphere is the closest to that predicted by the $\mathrm{F}_{4}$ model. The expression of the mechanism function is: $(1-\alpha)^{4}$. After averaging the activation energies and pre-exponential factors of the four heating rates, the reaction mechanism model was obtained as follows

$$
\frac{d \alpha}{d t}=8.26 \times 10^{11} \exp \left(\frac{-211691}{R T}\right)(1-\alpha)^{4},
$$

Table 4. Correlation coefficients corresponding to various mechanism function for the plot $\ln \left(\mathrm{F} / \mathrm{T}^{2}\right)-1 / \mathrm{T}$ at different heating rates.

\begin{tabular}{|c|c|c|c|c|c|}
\hline $\begin{array}{l}\text { Activation Energy } \\
\qquad(\mathrm{kJ} / \mathrm{mol})\end{array}$ & $\beta=5^{\circ} \mathrm{C} / \mathrm{min}$ & $\beta=10^{\circ} \mathrm{C} / \mathrm{min}$ & $\beta=20^{\circ} \mathrm{C} / \mathrm{min}$ & $\beta=40^{\circ} \mathrm{C} / \mathrm{min}$ & $\mathbf{R}$ \\
\hline $\mathrm{F}_{1}$ & 85.9009 & 90.2059 & 93.7321 & 97.1478 & -0.98982 \\
\hline $\mathrm{F}_{2}$ & 46.0787 & 48.1592 & 50.0159 & 52.5525 & -0.98913 \\
\hline $\mathrm{F}_{3}$ & 103.327 & 107.678 & 111.615 & 116.918 & -0.99107 \\
\hline $\mathrm{F}_{4}$ & 199.137 & 207.792 & 215.374 & 224.461 & -0.99922 \\
\hline $\mathrm{A}_{2}$ & 37.3654 & 39.4233 & 41.0745 & 42.6674 & -0.98643 \\
\hline $\mathrm{A}_{3}$ & 21.1869 & 22.4958 & 23.52189 & 24.5073 & -0.98121 \\
\hline $\mathrm{A}_{4}$ & 13.0976 & 14.0320 & 14.7456 & 15.4273 & -0.97261 \\
\hline $\mathrm{R}_{2}$ & 72.4191 & 76.1849 & 79.2192 & 81.9901 & -0.98259 \\
\hline $\mathrm{R}_{3}$ & 76.7291 & 80.6684 & 83.8604 & 86.8359 & -0.98531 \\
\hline $\mathrm{D}_{1}$ & 132.311 & 139.064 & 144.484 & 149.150 & -0.97677 \\
\hline $\mathrm{D}_{2}$ & 147.134 & 154.499 & 160.467 & 165.816 & -0.98217 \\
\hline $\mathrm{D}_{3}$ & 164.628 & 172.696 & 179.304 & 185.485 & -0.98728 \\
\hline $\mathrm{D}_{4}$ & 152.932 & 160.530 & 166.711 & 172.335 & -0.98407 \\
\hline
\end{tabular}




\subsection{Gas Phase Analysis}

\subsubsection{FTIR Analysis}

The Gram-Schmidt spectrum under inert atmosphere in Figure 2 represented the FTIR absorption intensity of the escaping gas during pyrolysis of the material, showing that there were only two peaks at $425^{\circ} \mathrm{C}$ and $557^{\circ} \mathrm{C}$, respectively, which were delayed compared to the corresponding DTG curve. This was due to the time delay between gas detection and gas generation in the FTIR spectrometer. The larger peak at $425^{\circ} \mathrm{C}$ indicated that the amount of gas escaping at this stage was higher, and had a higher infrared extinction coefficient.

Figure 9 shows the infrared spectral data of the gas at the characteristic temperatures determined by the DTG curve. At the characteristic temperature of $244{ }^{\circ} \mathrm{C}$, which was the first stage of mass loss, the products were carbon dioxide $\left(\mathrm{CO}_{2}: 2300-2400 \mathrm{~cm}^{-1}\right)$ and water $\left(\mathrm{H}_{2} \mathrm{O}: 3500-4000 \mathrm{~cm}^{-1}\right)$. The same phenomenon is observed by Ahamad [28] in the study of urea-formaldehyde/epoxy resin blends. Thus, this stage was not only a drying stage, but also a physical escape of small molecule gases. Obvious degradation behavior of the resin matrix occurred in the second stage, corresponding to the infrared spectral data at $410{ }^{\circ} \mathrm{C}$. Since the stretching vibration of saturated hydrocarbon $\mathrm{C}-\mathrm{H}$ is usually close to the frequency absorption of $3000 \mathrm{~cm}^{-1}$, it is speculated that there was methane gas $\left(\mathrm{CH}_{4}\right)$ according to the three peaks in the range of $2900-3170 \mathrm{~cm}^{-1}: 3045 \mathrm{~cm}^{-1}$, $3016 \mathrm{~cm}^{-1}$ and $2970 \mathrm{~cm}^{-1}$. In addition to water and carbon dioxide, carbon monoxide (CO: 2000-2200 $\mathrm{cm}^{-1}$ with double peaks at $2048 \mathrm{~cm}^{-1}$ and $2070 \mathrm{~cm}^{-1}$ ) and phenol (main peaks of $\mathrm{C}_{6} \mathrm{H}_{5} \mathrm{OH}: 3650,1608,1510,1260$ and $1176 \mathrm{~cm}^{-1}$ ) were also observed. The above products were considered to be the chain scission and depolymerization reactions of BPA epoxy resins [31], where $\mathrm{CO}$ and $\mathrm{CO}_{2}$ are mainly derived from the ether group (R-O-R'), methyl group $\left(-\mathrm{CH}_{3}\right)$, methylene group $\left(-\mathrm{CH}_{2}\right)$ and other carbon-containing functional groups. At $537^{\circ} \mathrm{C}$, carbon monoxide almost disappeared and turned into carbon dioxide, while the production of the other gas products decreased compared with that at $410{ }^{\circ} \mathrm{C}$.

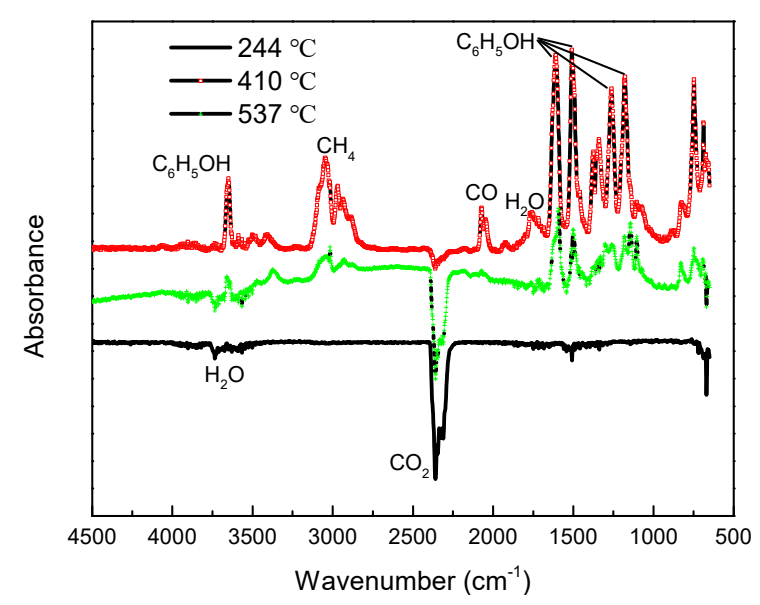

Figure 9. Spectra collected at 244,410 and $537^{\circ} \mathrm{C}$ of the degradation products of composites released during TGA $\left(20^{\circ} \mathrm{C} / \mathrm{min}\right.$-inert atmosphere).

\subsubsection{MS Analysis}

The following gas molecules were detected by mass spectrometry at a heating rate of $20^{\circ} \mathrm{C} / \mathrm{min}$ under inert atmosphere: $\mathrm{CH}_{2}(m / z=14), \mathrm{CH}_{4}(m / z=16), \mathrm{H}_{2} \mathrm{O}(m / z=18)$, $\mathrm{C}_{2} \mathrm{H}_{2}(m / z=26), \mathrm{CO}(m / z=28), \mathrm{C}_{2} \mathrm{H}_{4}(m / z=28), \mathrm{C}_{3} \mathrm{H}_{6}(m / z=42), \mathrm{CO}_{2}(m / z=44), \mathrm{C}_{3} \mathrm{H}_{8}$ $(m / z=44)$ and phenol $\mathrm{C}_{6} \mathrm{H}_{5} \mathrm{OH}(m / z=94)$.

According to the order of magnitude of ion current intensity, the classification analysis was carried out from high to low. As shown in Figure 10, the left ordinate shows the mass spectra of gas products with a mass-to-charge ratio of 28, which was supposed to be $\mathrm{CO}$ and/or $\mathrm{C}_{2} \mathrm{H}_{4}$. Additionally, there were three peaks in the curve, which respectively 
occurred at $125^{\circ} \mathrm{C}, 437^{\circ} \mathrm{C}$ and $920^{\circ} \mathrm{C}$. The peak with the largest ion current intensity appeared between 300 and $500{ }^{\circ} \mathrm{C}$, corresponding to the main decomposition peak in the DTG analysis, which was presumed to be the precipitation of $\mathrm{CO}$ gas, also observed by Tranchard [16] and Ahamad [28] and related to the certain amount of oxygen-containing groups in the polymer. The mass spectrum of phenol with the mass-to-charge ratio of 94 was shown on the right ordinate. Its precipitation range was $300-750{ }^{\circ} \mathrm{C}$, which covered the second and third mass loss stages, also corresponded to the peaks of infrared spectrum at $410{ }^{\circ} \mathrm{C}$ and $537^{\circ} \mathrm{C}$.

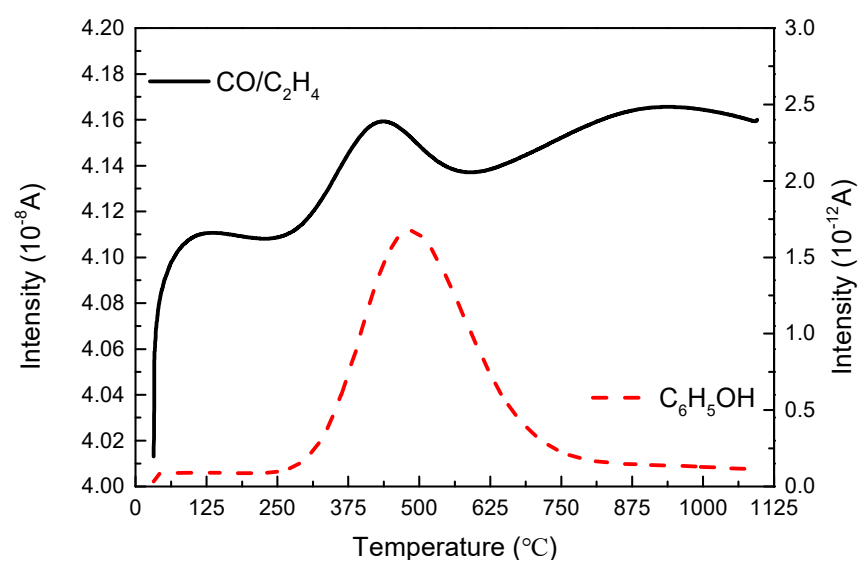

Figure 10. Intensity curves of $m / z=28$ and 94 degradation products of composite released during TGA $\left(20^{\circ} \mathrm{C} / \mathrm{min}\right.$-inert gas $)$.

For the detection result of water molecules in Figure 11, a trough appeared before $250{ }^{\circ} \mathrm{C}$, which corresponded to the first peak in the DTG curve, verifying that this was the drying stage. In addition, due to the pyrolysis reaction of the resin, the peak of water molecules appeared at $406^{\circ} \mathrm{C}$, which was ahead of the precipitation of $\mathrm{CO}$, indicating that the decomposition of the epoxy resin would preferentially produce water molecules, but mainly precipitated $\mathrm{CO}$. At this stage, the water produced by the thermal decomposition of epoxy resin mainly come from the breaking of the bonds of -OH functional groups.

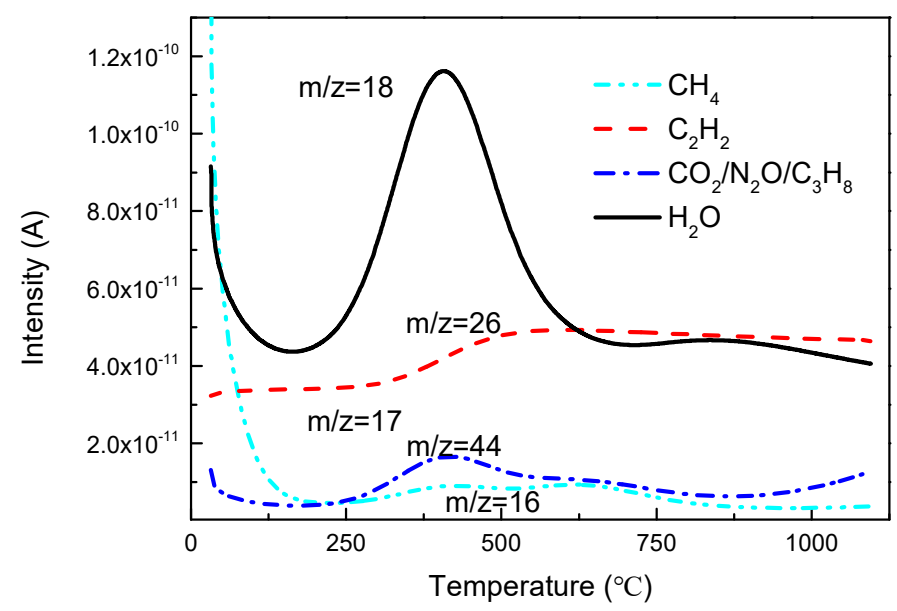

Figure 11. Intensity curves of $m / z=16,18,26$ and 44 degradation products of the composite released during TGA $\left(20^{\circ} \mathrm{C} / \mathrm{min}\right.$-inert atmosphere).

For the gas mass-to-charge ratio of $44, \mathrm{CO}_{2}, \mathrm{~N}_{2} \mathrm{O}$ and $\mathrm{C}_{3} \mathrm{H}_{8}$ were considered. However, the peak of the curve occurred at $410{ }^{\circ} \mathrm{C}$, ahead of $435{ }^{\circ} \mathrm{C}$, which was the precipitation temperature of the $\mathrm{CO}$ peak. Considering the sequence of reactions, $\mathrm{CO}$ mainly comes from the reforming of the $\mathrm{C}-\mathrm{O}$ group in the bisphenol A epoxy resin, and then combined with oxygen ions to form $\mathrm{CO}_{2}$. Therefore, it was speculated that the $\mathrm{m} / z=44$ mass spectrum 
curve was mainly represented by the $\mathrm{C}_{3} \mathrm{H}_{8}$ gas molecule. Since the reaction was carried out under an inert atmosphere, oxygen ions were supplied only by the material itself, which was also verified in the order of magnitude. It was speculated that the relatively small increasement of the amplitude of this curve afterwards might correspond to the formation of $\mathrm{CO}_{2}$.

The peak temperature of $\mathrm{C}_{2} \mathrm{H}_{2}$ gas molecules was close to the temperature of the third peak in the DTG curve, which was supposed to be the product of the second step of decomposition. It can be verified that the decomposition of carbon fiber reinforced epoxy resin matrix composite under inert atmosphere exhibits at least two steps (a major step and a secondary step).

\subsubsection{Effect of the Heating Rate on Gas Phase Products}

The increase of the heating rate leads to the phenomenon of thermal hysteresis, which is specifically manifested as the peak temperatures of $\mathrm{CO}, \mathrm{H}_{2} \mathrm{O}, \mathrm{CO}_{2}$ and $\mathrm{CH}_{4}$ ion flow all move toward the high temperature region with the increase of the heating rate. The production of $\mathrm{H}_{2} \mathrm{O}, \mathrm{CO}_{2}$ and $\mathrm{CH}_{4}$ all increase with the increase of heating rate as shown in Figure 12, which indicates that faster temperature rise promotes the reaction. The production of $\mathrm{CO}$ had a relatively obvious weak value at the low heating rate, but had little change at the heating rates of $10{ }^{\circ} \mathrm{C}, 20^{\circ} \mathrm{C}$ and $40^{\circ} \mathrm{C} / \mathrm{min}$.

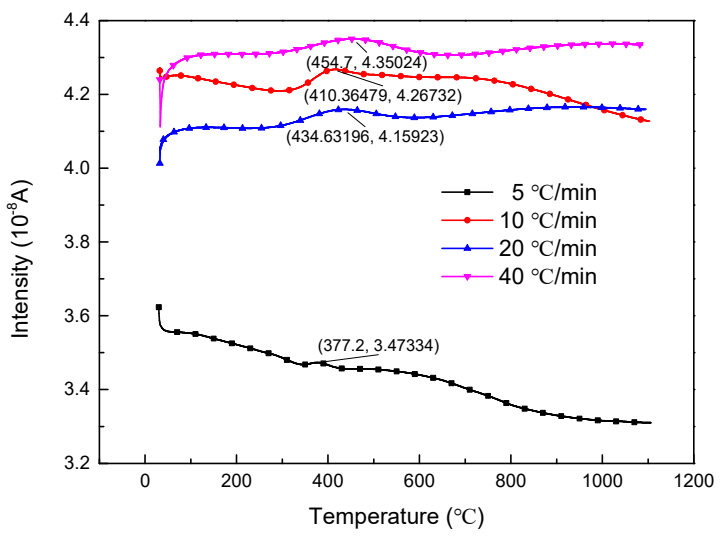

(a)

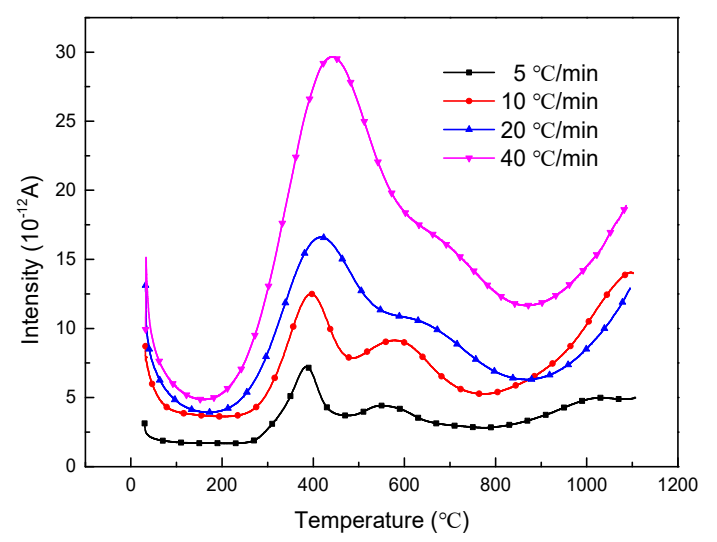

(c)

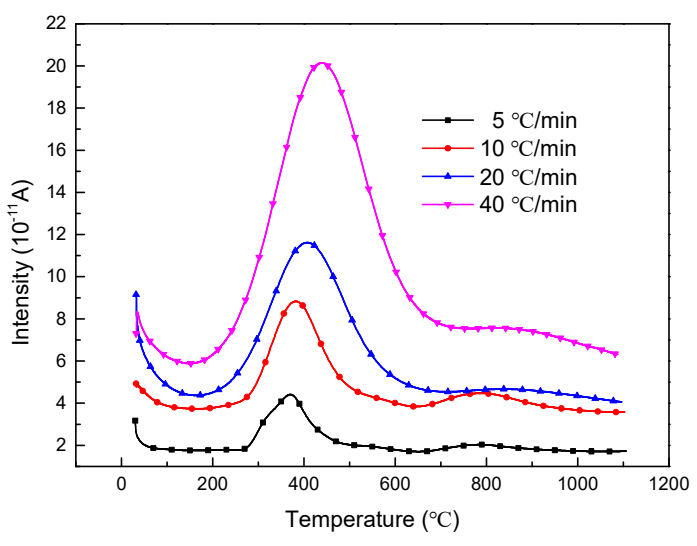

(b)

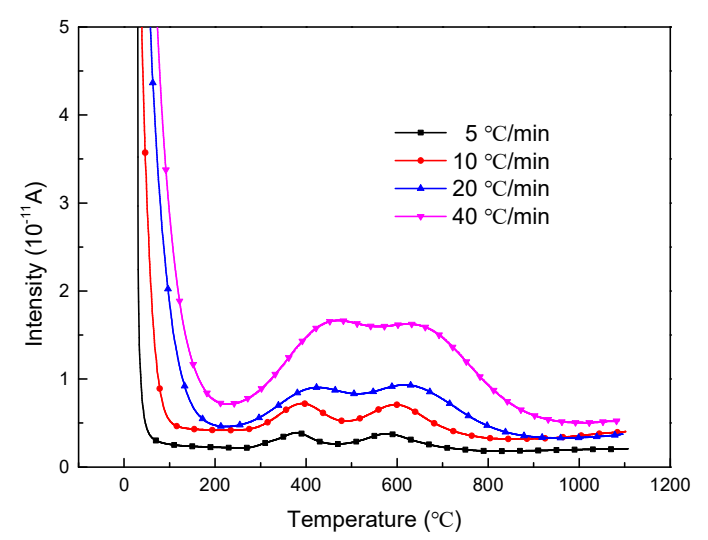

(d)

Figure 12. (a) $\mathrm{CO}$, (b) $\mathrm{H}_{2} \mathrm{O}$, (c) $\mathrm{CO}_{2}$ and (d) $\mathrm{CH}_{4}$ release against temperature with the heating rate during pyrolysis.

\section{Conclusions}

Thermal degradation of a new product of carbon fiber reinforced epoxy resin composite, namely BA3202, occurs in three steps under inert atmosphere, but in four steps under 
air atmosphere, respectively. The first two steps were almost the same. The first step is the physical changes, mainly water drying and carbon dioxide escape. The second step is the decomposition of the epoxy resin matrix, and the products are mainly methane, water, carbon monoxide, carbon dioxide and phenol. The third step in the inert atmosphere is the further pyrolysis of the polymer, in which phenol is formed, methane decreases, carbon monoxide basically disappears and carbon dioxide production increases. However, in air, the thermal oxidation of the carbonaceous residues and the intermolecular carbonization are observed. Furthermore, the last step in air is the oxidative decomposition of the carbon fibers. In addition, it is concluded that faster temperature rise can promote the reaction by the experimental comparison in different heating rates. These results provide a comprehensive and thorough understanding into the thermal behavior of CFRP in the thermal environment or fire, and can be used to support material selection and airworthiness certification of aviation structure.

Moreover, the activation energy value obtained by mechanism $\mathrm{F}_{4}$ is closed to that of the Kissinger/Friedman/Ozawa's method. Therefore, it can be inferred that the thermal degradation reaction mechanism of CFRP for this study obeys the $\mathrm{F}_{4}$ model, which indicates the order of reaction is 4 . As a result, the kinetic equation is obtained to support the application of carbon fiber reinforced epoxy matrix composite, such as modeling and assessment of thermal protection, fire resistance and lightning strikes.

Author Contributions: Methodology, H.L.; formal analysis, N.W.; investigation, X.H.; resources, H.L.; data curation, X.H.; writing-original draft preparation, H.Y.; writing-review and editing, H.L.; supervision, J.X. All authors have read and agreed to the published version of the manuscript.

Funding: This research received no external funding.

Institutional Review Board Statement: Not applicable.

Informed Consent Statement: Not applicable.

Data Availability Statement: The data presented in this study are available on request from the corresponding author.

Conflicts of Interest: The authors declare no conflict of interest.

\section{References}

1. Al-Rubaye, M.; Manalo, A.; Alajarmeh, O.; Ferdous, W.; Lokuge, W.; Benmokrane, B.; Edoo, A. Flexural behaviour of concrete slabs reinforced with GFRP bars and hollow composite reinforcing systems. Compos. Struct. 2020, 236, 111836. [CrossRef]

2. Mohammed, A.A.; Manalo, A.C.; Ferdous, W.; Zhuge, Y.; Vijay, P.V.; Pettigrew, J. Experimental and numerical evaluations on the behaviour of structures repaired using prefabricated FRP composites jacket. Eng. Struct. 2020, 210, 110358. [CrossRef]

3. Composite Aircraft Structure; FAA AC 20-107B; Federal Aviation Administration: Washington, DC, USA, 2010.

4. Stoliarov, S.I.; Crowley, S.; Walters, R.N.; Lyon, R.E. Prediction of the burning rates of charring polymers. Combust. Flame 2010, 157, 2024-2034. [CrossRef]

5. Linteris, G.T.; Lyon, R.E.; Stoliarov, S.I. Prediction of the gasification rate of thermoplastic polymers in fire-like environments. Fire Saf. J. 2013, 60, 14-24. [CrossRef]

6. Stoliarov, S.I.; Leventon, I.T.; Lyon, R.E. Two-dimensional model of burning for pyrolyzable solids. Fire Mater. 2014, 38, 391-408. [CrossRef]

7. Mckinnon, M.B.; Ding, Y.; Stoliarov, S.I.; Crowley, S.; Lyon, R.E. Pyrolysis model for a carbon fiber/epoxy structural aerospace composite. J. Fire Sci. 2016, 35, 36-61. [CrossRef]

8. Mouritz, A.P. Review of Smoke Toxicity of Fiber-Polymer Composites Used in Aircraft. J. Aircr. 2009, 46, 737-745. [CrossRef]

9. Speitel, L.C. Toxicity Assessment of Combustion Gases and Development of a Survival Model; DOT/FAA/AR-95/5; Federal Aviation Administration: Washington, DC, USA, 1995.

10. Speitel, L.C. Fractional effective dose model for post-crash aircraft survivability. Toxicology 1996, 115, 167-177. [CrossRef]

11. Tranchard, P.; Samyn, F.; Duquesne, S.; Estèbe, B.; Bourbigot, S. Modelling Behaviour of a Carbon Epoxy Composite Exposed to Fire: Part II-Comparison with Experimental Results. Materials 2017, 10, 470. [CrossRef]

12. Li, H.; Wang, N.; Han, X.; Fan, B.; Feng, Z.; Guo, S. Simulation of thermal behavior of glass fiber/phenolic composites exposed to heat flux on one side. Materials 2020, 13, 421. [CrossRef] [PubMed]

13. Li, H.; Fan, B.; Wang, N.; Han, X.; Feng, Z.; Guo, S. Thermal response study of carbon epoxy laminates exposed to fire. Polym. Compos. 2020, 41, 4757-4770. [CrossRef] 
14. Quintiere, J.G.; Walters, R.N.; Crowley, S. Flammability Properties of Aircraft Carbon-Fiber Structural Composite; DOT/FAA/AR-07/57; Federal Aviation Administration: Washington, DC, USA, 2007.

15. Tranchard, P.; Samyn, F.; Duquesne, S.; Estèbe, B.; Bourbigot, S. Modelling Behaviour of a Carbon Epoxy Composite Exposed to Fire: Part I-Characterisation of Thermophysical Properties. Materials 2017, 10, 494. [CrossRef] [PubMed]

16. Tranchard, P.; Duquesne, S.; Samyn, F.; Estèbe, B.; Bourbigot, S. Kinetic analysis of the thermal decomposition of a carbon fibre-reinforced epoxy resin laminate. J. Anal. Appl. Pyrolysis 2017, 126, 14-21. [CrossRef]

17. Brown, M.E.; Maciejewski, M.; Vyazovkin, S.; Nomen, R.; Sempere, J.; Burnham, A.; Opfermann, J.; Strey, R.; Anderson, H.L.; Kemmler, A.; et al. Computational aspects of kinetic analysis: Part a: The ictac kinetics project-data, methods and results. Thermochim. Acta 2000, 355, 125-143. [CrossRef]

18. Coats, A.W.; Redfern, J.P. Kinetic parameters from thermogravimetric data. Nature 1964, 201, 68-69. [CrossRef]

19. Simon, $P$. The isoconversional method for determination of energy of activation at constant heating rates. J. Anal 1983, 27, 95-102.

20. Friedman, H.L. Kinetics of thermal degradation of char-forming plastics from thermogravimetry: Application to a phenolic plastic. J. Polym. Sci. Part C Polym. Symp. 1964, 6, 183-195. [CrossRef]

21. Opfermann, J.; Kaisersberger, E. An advantageous variant of the ozawa-flynn-wall analysis. Thermochim. Acta 1992, 203, 167-175. [CrossRef]

22. Ozawa, T. A new method of analyzing thermogravimetric data. Bull. Chem. Soc. Jpn. 1965, 38, 1881-1886. [CrossRef]

23. Šesták, J.; Berggren, G. Study of the kinetics of the mechanism of solid-state reactions at increasing temperatures. Thermochim. Acta 1971, 3, 1-12. [CrossRef]

24. Burns, L.A.; Feih, S.; Mouritz, P.A. Fire-under-load Testing of Carbon Epoxy Composites. In Proceedings of the 47th AIAA Aerospace Sciences Meeting Including the New Horizons Forum and Aerospace Exposition, Orlando, FL, USA, 5-8 January 2009.

25. Chippendale, R.D. Modelling of the Thermal Chemical Damage Caused to Carbon Fibre Composites. Ph.D. Thesis, University of Southampton, Southampton, UK, 2013.

26. Deng, J.; Xu, L.; Liu, J.; Peng, J.; Han, Z.; Shen, Z.; Guo, S. Efficient method of recycling carbon fiber from the waste of carbon fiber reinforced polymer composites. Polym. Degrad. Stab. 2020, 182, 109419. [CrossRef]

27. Wang, B.; Wang, X.; Xu, N.; Shen, Y.; Lu, F.; Liu, Y.; Huang, Y.; Hu, Z. Recycling of carbon fibers from unsaturated polyester composites via a hydrolysis-oxidation synergistic catalytic strategy. Compos. Sci. Technol. 2021, 203, 108589. [CrossRef]

28. Ahamad, T.; Alshehri, S.M. Thermal degradation and evolved gas analysis: A polymeric blend of urea formaldehyde (UF) and epoxy (DGEBA) resin. Arab. J. Chem. 2013, 7, 1140-1147. [CrossRef]

29. Li, G.; Wu, F. Flame-Retardant Mechanism of Epoxy Resin Treated with Amino Resinous Intumescent Flame Retardant. Plast. Sci. Technol. 2010, 15-18.

30. Liu, Y.; Du, Z.; Zhang, C.; Li, H. Curing Reaction and Thermal Degradation of Bisphenol A Type Novolac Epoxy Resin with 4 , 4'-Diaminodiphenyl Ether. Chin. J. Appl. Chem. 2007, 3, 256-260.

31. Huang, N.; Liu, L.; Wang, X. Pyrolysis and Kinetics of Phenolic Resin by TG-MS Analysis. Aerosp. Mater. Technol. 2012, 2, 109-112.

32. Thomas, A.; Moinuddin, K.; Tretsiakova-Mcnally, S.; Joseph, P. A Kinetic Analysis of the Thermal Degradation Behaviours of Some Bio-Based Substrates. Polymers 2020, 12, 1830. [CrossRef]

33. Balart, R.; Garcia-Sanoguera, D.; Quiles-Carrillo, L.; Montanes, N.; Torres-Giner, S. Kinetic Analysis of the Thermal Degradation of Recycled Acrylonitrile-Butadiene-Styrene by non-Isothermal Thermogravimetry. Polymers 2019, 11, 281. [CrossRef]

34. Franco-Urquiza, E.A.; May-Crespo, J.F.; Escalante Velázquez, C.A.; Mora, R.P.; González García, P. Thermal Degradation Kinetics of $\mathrm{ZnO} /$ polyester Nanocomposites. Polymers 2020, 12, 1753. [CrossRef] [PubMed]

35. Krawiec, P.; Wargula, L.; Małoziec, D.; Kaczmarzyk, P.; Dziechciarz, A.; Czarnecka-Komorowska, D. The Toxicological Testing and Thermal Decomposition of Drive and Transport Belts Made of Thermoplastic Multilayer Polymer Materials. Polymers 2020, 12, 2232. [CrossRef] [PubMed]

36. Zhang, X.; Huang, R. Thermal Decomposition Kinetics of Basalt Fiber-Reinforced Wood Polymer Composites. Polymers 2020, 12, 2283. [CrossRef]

37. GB/T 19267.12-2008. Physical and Chemical Examination of Trace Evidence in Forensic Sciences-Part 12: Thermoanalysis; China National Standardization Administration: Beijing, China, 14 August 2008.

38. ASTM E2550-17. Standard Test Method for Thermal Stability by Thermogravimetry; ASTM International: West Conshohocken, PA, USA, 2017.

39. GB/T 19267.1-2008. Physical and Chemical Examination of Trace Evidence in Forensic Sciences_Part 1: Infrared Absorption Spectrometry; China National Standardization Administration: Beijing, China, 14 August 2008.

40. GB/T 19267.7-2008. Physical and Chemical Examination of Trace Evidence in Forensic Sciences_Part 7: Gas Chromatography/Mass Spectrometry; China National Standardization Administration: Beijing, China, 14 August 2008.

41. Marker, T.R.; Speitel, L.C. Development of a Laboratory-Scale Test for Evaluating the Decomposition Products Generated Inside an Intact Fuselage during a Simulated Postcrash Fuel Fire; DOT/FAA/AR-TN07/15; Federal Aviation Administration: Washington, DC, USA, 2008.

42. Shao, J.; Yan, R.; Chen, H.; Wang, B.; Lee, D.; Liang, D. Pyrolysis Characteristics and Kinetics of Sewage Sludge by Thermogravimetry Fourier Transform Infrared Analysis. Energy Fuels 2008, 2, 38-45. [CrossRef]

43. Ding, H.; Zhang, J.; Cai, P. Thermal Degradation of DGEBA/EDA Epoxy Resin. Polym. Mater. Sci. Eng. 2011, $27,83-85$. 
44. Yang, X.; Chen, R. Study on curing kinetics of bisphenol a epoxy resin by pyrolysis gas chromatography (I)—Determination of epoxy value. China Adhes. 1987, 3, 24-25.

45. Feih, S.; Mouritz, A.P. Tensile properties of carbon fibres and carbon fibre-polymer composites in fire. Compos. Part A 2012, 43, 765-772. [CrossRef]

46. Xu, Y.; Yang, Y.; Zhang, Y.; Wang, Z. Pyrolysis characteristics of unidirectional carbon fiber/epoxy prepreg. Acta Mater. Compos. Sin. 2018, 35, 2442-2448.

47. Kissinger, H.E. Reaction Kinetics in Differential Thermal Analysis. Anal. Chem. 1957, 29, 1702-1706. [CrossRef]

48. Bai, Y. Material and Structural Performance of Fiber-Reinforced Polymer Composites at Elevated and High Temperatures. Ph.D. Thesis, School of Architecture, Civil and Environmental Engineering, Lausanne, Switzerland, 2009.

49. Lee, J.Y.; Shim, M.J.; Kim, S.W. Thermal decomposition kinetics of an epoxy resin with rubber-modified curing agent. J. Appl. Polym. Sci. 2001, 81, 479-485. [CrossRef] 